\title{
Utilização de biofertilizante e adubação química em capim-piatã (Brachiaria brizantha)
}

\section{Use of biofertilizer and chemical fertilizer on piatã-grass (Brachiaria brizantha)}

\author{
Thiago T. Biserra*, Luísa M. Paiva, Henrique J. Fernandes, Camila F. D. Duarte, Alex C. Fleitas \\ e Ademir 0 da Silva
}

Universidade Estadual de Mato Grosso do Sul, Unidade Universitária de Aquidauana (UEMS/UUA), Aquidauana, MS. Brasil (*E-mail: thiagotrento@hotmail.com)

http://dx.doi.org/10.19084/RCA16006

Recebido/received: 2016.01 .13

Recebido em versão revista/received in revised form: 2016.06 .03

Aceite/accepted: 2016.06.07

\begin{abstract}
R E S U M O
Objetivou-se avaliar o desenvolvimento de capim-piatã (Brachiaria brizantha) recebendo níveis de adubação orgânica (0, 1,0, 2,0, 3,0 e 4,0 L de biofertilizante líquido de esterco bovino por vaso), em diferentes condições de adubação química (sem adubo químico - controle, com aplicação de 50 e 100\% da recomendação de adubação química). Observou-se efeito $(\mathrm{P}<0,05)$ do biofertilizante associado ou não com adubação química em todas as características morfogênicas e estruturais do capim-piatã, exceto na duração de vida das folhas com 100\% da adubação química. Observou-se ainda efeito $(\mathrm{P}<0,05)$ linear do biofertilizante na taxa de alongamento foliar e senescência foliar em todas as condições de adubação química. Já quando se adotou uma dose de $50 \%$ da recomendação, observou-se efeito $(\mathrm{P}<0,05)$ linear na taxa de aparecimento foliar, filocrono e número de folhas vivas. A substituição total ou parcial da adubação química pelo suprimento com biofertilizante pode ser promissor no desenvolvimento do capim-piatã.
\end{abstract}

Palavras-chave: biofertilização, Brachiaria brizantha cv. BRS Piatã, caracterização morfogênica, desenvolvimento sustentável.

\begin{abstract}
A B S T R A C T
A study was carried out aimed at evaluating the development of piatã-grass (Brachiaria brizantha) receiving different levels of organic fertilization (0, 1.0, 2.0, 3.0 and 4.0 L of biofertilizers liquid manure) in different conditions of chemical fertilizer (no chemical fertilizer - control, with application of 50 and $100 \%$ of the chemical fertilizer recommendation). It was observed effect $(\mathrm{P}<0,05)$ with or without biofertilizer with chemical fertilizer in all morphogenic and structural characteristics of piatã-grass except the life span of leaves with $100 \%$ of chemical fertilizer. It was also observed linear effect $(\mathrm{P}<0.05)$ of biofertilizer in leaf elongation rate and leaf senescence in all conditions of chemical fertilizer. With $50 \%$ of the chemical recommendation, there was a linear effect $(\mathrm{P}<0.05)$ in leaf appearance rate, phyllochron and number of live leaves. The total or partial replacement of chemical fertilizer with biofertilizer may be promising in the development of piatã-grass.
\end{abstract}

Keywords: biofertilization, Brachiaria brizantha cv. BRS Piatã, morphogenic characterization, sustainable development.

\section{INTRODUÇÃO}

Em virtude da baixa disponibilidade de nutrientes na maioria dos solos brasileiros a produção forrageira apresenta limitações. Assim, a utilização de técnicas de manejo que visem aumentar a nutrição das plantas é de fundamental importância na produção forrageira.
A adubação de pastagens é uma prática indispensável, contribuindo ainda para a conservação do solo, prolongando sua vida útil e diminuindo os riscos de degradação. Teles et al. (2011), ao avaliarem os efeitos da adubação com NPK em pastagens de Brachiaria brizantha cv. MG-4, observaram aumento na produção de matéria seca $\left(\mathrm{g} \mathrm{vaso}^{-1}\right)$ das folhas, matéria seca dos colmos e matéria seca total. 
Os autores constataram ainda efeitos positivos na qualidade da forrageira.

Primoet al.(2010) destacaramqueoempregodefontes alternativas, como aproveitamento de resíduos da própria atividade pecuária, mostrava-se eficiente e sustentável, em função da reciclagem de nutrientes no sistema e redução da contaminação ambiental decorrente da deposição inadequada de resíduos.

Orrico Júnior et al. (2012) relataram que, das fontes de matéria orgânica, o esterco bovino é considerado um dos poucos com grande potencial como fertilizante, podendo ser utilizado para incrementar a produção forrageira.

O biofertilizante é um subproduto obtido da fermentação de resíduos agrícolas ou dejetos de animais que podem substituir ou complementar a adubação química (Sousa et al., 2013). Estes podem ser utilizados nos solos ou em tratamentos foliares (Lima et al., 2012).

O biofertilizante proveniente de dejetos de bovinos apresenta em sua composição macro e micronutrientes e microrganismos responsáveis pela decomposição da matéria orgânica, e ainda sais e compostos orgânicos e inorgânicos que atuam na melhoria não só da nutrição das plantas, mas também na atividade microbiana do solo (Penteado, 2007).

Mueller et al. (2013) observaram que a associação entre biofertilizante líquido de esterco bovino e adubação química, proporcionou efeito positivo às plantas, aumentado à produtividade de tomates (Solanum lycopersicum L.) Isso, em função do melhor aproveitamento dos nutrientes, através do sincronismo de liberação ao longo de seu desenvolvimento (Shehata et al., 2010).

No entanto, para que os dejetos de animais possam ser utilizados de forma eficiente como adubo orgânico, é necessário estudar o efeito das diferentes doses aplicadas pois só assim será possível estabelecer quantidades que promovam o maior crescimento e desenvolvimento da planta, sem ocasionar o excesso de nutrientes no solo (Souto et al., 2005).

Nesse contexto, objetivou-se avaliar o desenvolvimento do capim-piatã recebendo níveis de adubação orgânica (biofertilização), em diferentes condições de adubação química.

\section{MATERIAL E MÉTODOS}

O experimento foi desenvolvido no setor de ambientes protegidos, em estufa agrícola, na Fazenda UEMS/Unidade Universitária de Aquidauana, localizada a $20^{\circ} 28^{\prime}$ de latitude sul e longitude de $55^{\circ} 48^{\prime}$ a oeste de Greenwich, apresentando uma altitude média de $149 \mathrm{~m}$. O clima da região, segundo classificação de Köppen, é Tropical Savana (Aw), dividido em duas estações: a chuvosa e a seca. O experimento foi realizado em vasos e conduzido de agosto a dezembro de 2013.

Os tratamentos consistiram de quatro doses de biofertilizante líquido de esterco bovino $(1,0 ; 2,0$; 3,0 e 4,0 L vaso-1) e um controle (sem biofertilizante), avaliados sob três condições de adubação química (sem adubo químico, com aplicação de $50 \%$ da recomendação de adubação química e com aplicação de $100 \%$ da recomendação de adubação química). Para cada dose de biofertilizante líquido, em cada condição de adubação química, utilizaram-se quatro repetições, totalizando 60 unidades experimentais.

O biofertilizante foi preparado com dejetos de vacas leiteiras coletados na Chácara São Cristóvão, no distrito de Camisão/MS e preparado conforme proposto por Penteado (2007). Essa preparação consistiu na fermentação por 30 dias, na ausência de ar, de uma mistura contendo esterco bovino fresco e água na proporção de 50\% (volume/ volume).

Para se obter o sistema anaeróbio, a mistura foi colocada em uma bombona plástica com capacidade para 200 L (Penteado, 2007). Após 30 dias de fermentação dos dejetos, o material foi peneirado em peneiras de 4,0 $\mathrm{mm}$ de malha, e separada a parte líquida da sólida. As características químicas do biofertilizante líquido constam no Quadro 1.

O solo utilizado foi classificado como Latossolo vermelho distrófico (Embrapa, 2006), apresentando as características físico-químicas que se apresentam no Quadro 2. 
Quadro 1 - Teores de macro e micronutrientes do biofertilizante líquido de esterco bovino usado no experimento

\begin{tabular}{|c|c|c|c|c|c|c|c|c|c|c|}
\hline $\mathbf{N}$ & $\mathbf{P}$ & $\mathrm{K}$ & $\mathrm{Ca}$ & $\mathrm{Mg}$ & Al & $\mathrm{Cl}$ & $\mathrm{Fe}$ & Mn & $\mathrm{Cu}$ & $\mathrm{Zn}$ \\
\hline \multicolumn{11}{|c|}{$\mathrm{g} \mathrm{L}^{-1}$} \\
\hline 0.496 & 0.128 & 0.095 & 0.41 & 1.952 & 0.009 & $<0.0001$ & 0.04 & 0.024 & 0.002 & 0.012 \\
\hline
\end{tabular}

Quadro 2 - Características físico-químicas do solo utilizado no experimento

\begin{tabular}{|c|c|c|c|c|c|c|c|c|c|c|}
\hline pH em água & $\mathbf{P}$ & M.O. & Textura & K & $\mathrm{Ca}$ & $\mathrm{Mg}$ & Al & $\mathrm{H}+\mathrm{Al}$ & $S$ & $\mathbf{T}$ \\
\hline & $\mathrm{mg} \mathrm{dm}^{-3}$ & $\mathrm{~g} \mathrm{dm}^{-3}$ & $\%$ & \multicolumn{7}{|c|}{ mmolc dm ${ }^{-3}$} \\
\hline 5,40 & 2,90 & 9,00 & 2,00 & 0,40 & 6,00 & 5,00 & 8,00 & 30,00 & 14,0 & 41,14 \\
\hline
\end{tabular}

Foram usados vasos com capacidade de $15 \mathrm{dm}^{3}$ de solo e deixados para estabilização de suas características por 28 dias, e mantidos a 80\% da capacidade de retenção de água do solo. Simultaneamente, o capim-piatã foi semeado em bandejas plásticas de 200 células, com substrato comercial e mantido por 28 dias.

Após o período de estabilização foram transplantadas 10 plântulas por vaso e sete dias depois, aplicada a adubação química nos vasos correspondentes aos seus tratamentos. A fonte de nitrogênio $(\mathrm{N})$ utilizada foi o Nitro Mais ${ }^{\circledR}(45 \%$ de $N)$ (Fertilizantes Heringer, Viana, ES), a fonte de fósforo ( $\mathrm{P})$ foi superfosfato simples $\left(16 \%\right.$ de $\left.\mathrm{P}_{2} \mathrm{O}_{5}\right) \mathrm{e}$ de potássio $(\mathrm{K})$, o cloreto de potássio $\left(42 \%\right.$ de $\left.\mathrm{K}_{2} \mathrm{O}\right)$.

As quantidades de N-P-K recomendadas após a análise química do solo foram: 150, 40 e $50 \mathrm{~kg} \mathrm{ha}^{-1}$, respectivamente. Para $100 \%$ da recomendação foram aplicados: $2,52 \mathrm{~g}$ vaso $^{-1}$ de N, 1,67 $\mathrm{g} \mathrm{vaso}^{-1}$ de $\mathrm{P} \mathrm{e} 0.64 \mathrm{~g}$ vaso $^{-1}$ de $\mathrm{Ke}$, para $50 \%$ da recomendação: $1.26 \mathrm{~g}_{\text {vaso }}{ }^{-1}$ de $\mathrm{N}, 0.84 \mathrm{~g}_{\text {vaso }}-1$ de $\mathrm{P}$ e $0.32 \mathrm{~g}$ vaso $^{-1}$ de $\mathrm{K}$ respectivamente. Os adubos foram incorporados em todo solo contido no vaso. As doses de nitrogênio foram divididas em três aplicações iguais, com intervalos de 28 dias, até aos 63 dias após o transplantio.

Após 14 dias de cultivo, foi realizado o desbaste, salvaguardando-se quatro plantas semelhantes por vaso. Após 15 dias e quinzenalmente a partir daí, até dia 74 após o transplantio, foram realizadas as aplicações de biofertilizante com 200, 400, 600 e $800 \mathrm{ml}^{\text {vaso }}{ }^{-1}$, via foliar, correspondentes aos tratamentos considerados. Os vasos foram irrigados diariamente, duas vezes ao dia.

Vinte e um dias após o transplantio realizou-se corte de uniformização das plantas a $15 \mathrm{~cm}$ de altura da superfície do solo, conforme proposto por Orrico Júnior et al. (2012). Após o corte de uniformização foram demarcados, com fios de arame colorido dois perfilhos em duas plantas de cada vaso, para realização das mensurações das plantas.

Estes perfilhos até aos 90 dias após o transplantio, foram medidos semanalmente quanto à altura do pseudocolmo e ao comprimento de cada lâmina foliar, sendo registradas as ocorrências de senescência, quebra (corte), morte e expansão da lâmina foliar. Essas medidas foram utilizadas na determinação de: taxa de aparecimento foliar (folha perfilho-1 dia $^{-1}$ ): quociente entre o número de folhas por perfilho surgidas no período avaliado e número de dias do período; filocrono (dias): inverso da taxa de aparecimento de folhas (dias folha ${ }^{-1}$ perfilho ${ }^{-1}$ ); taxa de expansão de folhas ( $\mathrm{cm}$ perfilho- $\mathrm{dia}^{-1}$ ): variação média no comprimento da folha em expansão durante o período de avaliação; taxa de senescência de folhas ( $\mathrm{cm}$ perfilho-1 $\left.\mathrm{dia}^{-1}\right)$ : variação média no comprimento da porção senescente da folha, resultado do produto entre o comprimento da lâmina foliar senescente e a proporção de tecido senescente correspondente, observada ao longo do período de avaliação; número de folhas vivas: contagem do número de folhas vivas, não senescentes; duração de vida das folhas (dias); e taxa de alongamento de colmo $\left(\mathrm{cm}\right.$ perfilho $\left.{ }^{-1} \mathrm{dia}^{-1}\right)$ : variação média no comprimento do pseudocolmo durante o período de avaliação. 
Também foram contados, a cada 28 dias, até aos 84 dias após o transplantio, o número de perfilhos vivos por vaso, realizado em duas plantas em cada vaso.

As interações entre adubação química e com o biofertilizante foram avaliadas e retiradas do modelo por não serem significativas. Os dados foram então analisados para o efeito do biofertilizante segundo um delineamento inteiramente casualizado, dentro de cada condição de adubação química. A soma de quadrados de tratamentos foi particionada em contrastes ortogonais para se avaliar os efeitos de uso de biofertilizante e os efeitos lineares e quadráticos do nível de biofertilizante. Utilizou-se o pacote estatístico SAS v 9.3 (SAS Institute Inc. Cary, CA). Adotou-se um nível de significância de 5\% em todas as análises estatísticas.

\section{RESULTADOS E DISCUSSÃO}

Observou-se efeito $(\mathrm{P}<0,05)$ douso donível de biofertilizante aplicado sobre todas as características morfogênicas do capim-piatã, em todas as condições de adubação química, exceto a duração de vida das folhas (DVF) com $100 \%$ da adubação química recomendada. Observou-se ainda efeito $(\mathrm{P}<0,05)$ linear do nível de biofertilizante aplicado sobre a taxa de alongamento foliar (TAlF) e taxa de senescência foliar (TSeF) (Quadro 3).

O efeito do uso das doses de biofertilizante sobre a TAlF, em todas as condições de adubação química, e linear positivo nos níveis sem adubação e com $50 \%$ da adubação química recomendada, se deve ao efeito do azoto $(\mathrm{N})$ presente no biofertilizante sobre a produção de novas células, com consequente aumento na área foliar (Volenec e Nelson, 1983). De acordo com Skinner e Nelson (1995), o N atua na base da folha em expansão, no interior do pseudocolmo, proporcionando esse maior alongamento foliar.

Apesar do N ser o principal responsável por grande parte do crescimento dos tecidos vegetais, vale enfatizar ainda a importância do P e K presentes no biofertilizante. Esses nutrientes participam nas diversas funções fisiológicas e metabólicas,

Quadro 3 - Taxa de alongamento foliar (TAIF), taxa de senescência foliar (TSeF), taxa de alongamento de colmo (TAIC) e duração de vida das folhas (DVF) do capim-piatã cultivado em ambiente protegido, recebendo biofertilizante com doses de adubo químico

\begin{tabular}{|c|c|c|c|c|c|c|c|c|}
\hline \multirow{2}{*}{$\begin{array}{c}\text { Adubação } \\
\text { Química }\end{array}$} & \multicolumn{5}{|c|}{ Doses de Biofertilizante (L) } & \multirow{2}{*}{ CV $(\%)$} & \multicolumn{2}{|c|}{$\begin{array}{c}\text { Valor P Efeitos } \\
\text { dose de biofertilizante }\end{array}$} \\
\hline & 0,0 & 1,0 & 2,0 & 3,0 & 4,0 & & $\begin{array}{c}\text { Uso de Bi- } \\
\text { ofertilizante }\end{array}$ & $\begin{array}{l}\text { Efeito } \\
\text { Linear }\end{array}$ \\
\hline \multicolumn{9}{|c|}{ TAlF (cm perfilho ${ }^{-1}$ dia $\left.^{-1}\right)$} \\
\hline Sem adubo & 1,27 & 1,32 & 1,53 & 1,75 & 1,74 & 9,96 & 0,002 & 0,001 \\
\hline $50 \%$ & 1,40 & 1,56 & 1,77 & 2,01 & 2,03 & 11,23 & 0,001 & 0,004 \\
\hline $100 \%$ & 1,44 & 1,98 & 2,04 & 2,13 & 2,14 & 5,51 & $<0,001$ & 0,05 \\
\hline \multicolumn{9}{|c|}{ TSeF $\left(\mathrm{cm}\right.$ perfilho ${ }^{-1}$ dia $\left.^{-1}\right)$ : } \\
\hline Sem adubo & 0,33 & 0,87 & 1,06 & 1,43 & 1,57 & 16,53 & $<0,001$ & $<0,001$ \\
\hline $50 \%$ & 0,42 & 1,05 & 1,08 & 1,23 & 1,60 & 20,70 & $<0,001$ & 0,003 \\
\hline $100 \%$ & 0,85 & 1,26 & 1,59 & 1,88 & 1,90 & 17,34 & $<0,001$ & 0,003 \\
\hline \multicolumn{9}{|c|}{ TAlC $\left(\mathrm{cm}\right.$ perfilho ${ }^{-1}$ dia $\left.^{-1}\right)$ : } \\
\hline Sem adubo & 0,60 & 0,77 & 0,78 & 0,85 & 0,80 & 10,10 & 0,0003 & 0,68 \\
\hline $50 \%$ & 0,67 & 0,76 & 0,83 & 0,90 & 0,86 & 9,87 & 0,001 & 0,07 \\
\hline $100 \%$ & 0,73 & 0,81 & 0,85 & 0,93 & 0,92 & 9,58 & 0,004 & 0,07 \\
\hline \multicolumn{9}{|c|}{ DVF (dias) } \\
\hline Sem adubo & 88,87 & 75,53 & 77,00 & 77,53 & 72,10 & 6,70 & $<0,001$ & 0,36 \\
\hline $50 \%$ & 86,16 & 79,98 & 78,68 & 79,98 & 84,29 & 4,60 & 0,02 & 0,12 \\
\hline $100 \%$ & 81,90 & 86,66 & 84,00 & 81,02 & 84,56 & 8,40 & 0,58 & 0,67 \\
\hline
\end{tabular}


além de melhorar a absorção do $\mathrm{N}$ pelas plantas (Andrade et al., 2000).

O aumento na TAlF com as doses de biofertilizante tem reflexo positivo no fluxo de tecidos das plantas, pois está diretamente correlacionado com o rendimento forrageiro, pelo aumento na relação carbono e nitrogênio tal como consideraram Alexandrino et al. (2004). Estes autores afirmaram também que essa variável é extremamente influenciada pela aplicação de $\mathrm{N}$.

Este aumento na dinâmica de desenvolvimento das folhas é corroborado também pelo aumento registrado na senescência foliar. Segundo Martuscello et al. (2006) o processo de senescência é resultado da última fase de desenvolvimento de uma folha, iniciando após sua completa expansão, cuja intensidade se acentua progressivamente com o aumento da área foliar, em decorrência do sombreamento das folhas inseridas na porção inferior do colmo.

Observou-se neste experimento que, após a aplicação de biofertilizante, a quantidade de perdas de tecido foliar por senescência aumentou consideravelmente. Isso mostra que o biofertilizante foi capaz de proporcionar maior precocidade às plantas, elevando a senescência foliar nos perfilhos. Segundo Da Silva et al. (2012), o N acelera o fluxo e renovação dos tecidos das plantas, com consequente aumento na TSeF.

Pode-se observar que as plantas sem adubação química e sem receber o biofertilizante apresentaram uma menor TSeF. Isso se deve a uma estratégia imputada pelas plantas na ausência de $\mathrm{N}$ para permanecerem vivas, graças à diminuição do seu metabolismo (Martuscello et al., 2006).

O aumento na taxa de alongamento do colmo (TAlC) com o uso biofertilizante também pode ser explicado pelo aumento do $\mathrm{N}$ disponível para o crescimento e desenvolvimento forrageiro (Oliveira et al., 2007; Gomes et al., 2012). Este aumento no alongamento do colmo é de fundamental importância para o dossel forrageiro, pois facilita a captação de radiação fotossinteticamente ativa pelas folhas das plantas (Pereira et al., 2011).

A redução na DVF nos níveis sem adubação e com $50 \%$ da adubação química recomendada com o uso biofertilizante pode ser explicada pelo efeito deste, estimulando o crescimento da planta, com consequente concorrência por captação de luz para realização da fotossíntese (Mazzanti et al., 1994).

Por outro lado, com um nível de $100 \%$ da adubação química recomendada não se observou efeito $(\mathrm{P}<0,05)$ do uso ou das doses de biofertilizante. Isso se deve ao aumento na disponibilidade de nutrientes às plantas, fazendo com que alcançassem seu período máximo de duração de vida, com consequente estabilização na DVF (Santos et al., 2009).

Sobre este aspecto, Martuscello et al. (2005) relataram que as folhas das gramíneas são órgãos de crescimento de vida útil limitada, uma vez atingido seu tamanho final, permanecem no perfilho por certo período, entram em processo de senescência e morrem. Isto mostra que o conhecimento da dinâmica de crescimento do capim-piatã por meio de suas características morfogênicas e estruturais recebendo adubação, torna-se de fundamental importância na definição de estratégias racionais de manejo.

A média geral da DVF do capim-piatã recebendo biofertilizante com adubação química foi de 81.21 dias. Esse resultado é semelhante aos encontrados por Silveira et al. (2010), que, ao avaliarem oito cultivares de Brachiaria brizantha em crescimento livre, com período de avaliação de 178 dias, registaram que a cv. Piatã apresentou DVF de 78.00 dias.

Segundo Mazzanti etal. (1994) a redução da DVF com aumento das doses de $\mathrm{N}$ aplicado no solo, é resultante do aumento da taxa de alongamento foliar, em função da competição por luz. Já Martuscello et al. (2005) explicam ainda que a redução da DVF com o aumento das doses de nitrogênio é explicada pela renovação de tecidos nas plantas.

Observou-se efeito $(\mathrm{P}<0,05)$ do uso de biofertilizante aplicado sobre as características morfogênicas do capim-piatã em todas as condições de adubação química. Já o efeito linear do nível de biofertilizante apenas se tornou evidente $(\mathrm{P}<0,05)$ quando se trabalhou com $50 \%$ da adubação química (Quadro 4). 
Quadro 4 - Taxa de aparecimento foliar (TApF) e filocrono do capim-piatã cultivado em ambiente protegido, recebendo biofertilizante com doses de adubo químico

\begin{tabular}{|c|c|c|c|c|c|c|c|c|}
\hline \multirow{2}{*}{$\begin{array}{l}\text { Adubação } \\
\text { Química }\end{array}$} & \multicolumn{5}{|c|}{ Doses de Biofertilizante (L) } & \multirow{2}{*}{ CV $(\%)$} & \multicolumn{2}{|c|}{$\begin{array}{c}\text { Valor P Efeitos } \\
\text { dose de biofertilizante }\end{array}$} \\
\hline & 0,0 & 1,0 & 2,0 & 3,0 & 4,0 & & $\begin{array}{c}\text { Uso de Bi- } \\
\text { ofertilizante }\end{array}$ & $\begin{array}{l}\text { Efeito } \\
\text { Linear }\end{array}$ \\
\hline \multicolumn{9}{|c|}{ TApF (folha perfilho ${ }^{-1}$ dia $^{-1}$ ): } \\
\hline Sem adubo & 0,07 & 0,09 & 0,10 & 0,10 & 0,10 & 10,10 & 0,0002 & 0,08 \\
\hline $50 \%$ & 0,08 & 0,08 & 0,10 & 0,10 & 0,10 & 10,92 & 0,003 & 0,03 \\
\hline $100 \%$ & 0,09 & 0,09 & 0,10 & 0,11 & 0,10 & 10,61 & 0,02 & 0,34 \\
\hline \multicolumn{9}{|c|}{ Filocrono (dias folha-1 perfilho $^{-1}$ ) } \\
\hline Sem adubo & 13,47 & 10,46 & 9,83 & 9,80 & 9,37 & 8,46 & $<0,001$ & 0,10 \\
\hline $50 \%$ & 12,61 & 11,44 & 10,17 & 9,45 & 9,63 & 11,17 & 0,002 & 0,04 \\
\hline $100 \%$ & 11,43 & 10,46 & 9,60 & 8,85 & 9,46 & 16,11 & 0,01 & 0,22 \\
\hline
\end{tabular}

O aumento na taxa de aparecimento foliar (TApF) com o uso de biofertilizante também deve-se principalmente ao $\mathrm{N}$ presente no biofertilizante $\mathrm{e}$ seu efeito sobre o crescimento da planta, como já discutido. Segundo Oliveira et al. (2007), o N atua no alongamento dos entrenós, empurrando a folha nova para fora da bainha da folha precedente.

O aumento na TApF com as doses de biofertilizante é de fundamental importância no fechamento do dossel forrageiro, pois cada nova folha formada no colmo resulta da formação de um novo fitômero, ou seja, da formação de novas gemas axilares. Isso promove um incremento na interceptação de luz, para realização da fotossíntese (Fagundes et al., 2006).

O aumento na dinâmica de aparecimento das folhas é corroborado também pela diminuição registrada no filocrono. O filocrono é diretamente influenciado pela taxa de aparecimento de folhas, já que é o seu inverso, e reflete o intervalo de tempo (dias) entre o aparecimento de duas folhas sucessivas no perfilho. Essa redução do filocrono com o uso de biofertilizante em condições de $50 \%$ de aplicação da adubação deve-se à influência do $\mathrm{N}$ presente no biofertilizante sobre os diversos processos fisiológicos das plantas, com consequente aumento no aparecimento de folhas nos perfilhos, o que é desejável.

Observou-se efeito $(\mathrm{P}<0,05)$ do uso de biofertilizante, em todas as condições de adubação química sobre o número de folhas vivas (NFV), e quando não se adotou adubação química sobre o número de perfilhos vivos por vaso $(\mathrm{P}<0,05)$. Observou-se ainda um efeito $(\mathrm{P}<0,05)$ linear do nível de biofertilizante sobre o NFV quando se trabalhou com $50 \%$ da recomendação de adubação química (Quadro 5).

O aumento no NFV com o uso de biofertilizante deve-se ao fornecimento de nutrientes via biofertilização, estimulando a produção de novos tecidos. Comportamento semelhante também foi observado entre a TApF e o NFV, e consequentemente, compensação na taxa de senescência.

Pode-se observar que as plantas sem adubação química e sem receber o biofertilizante apresentaram maior DVF e menor NFV. Isso provavelmente pode ser associado ao efeito do $\mathrm{N}$ antecipando o processo de senescência nas plantas, com consequente translocação de nutrientes para auxiliar a expansão de novas folhas (Martuscello et al., 2006).

Segundo Alexandrino etal. (2004) as plantas adubadas com $\mathrm{N}$ irão atingir seu número máximo de folhas vivas por perfilho mais precocemente em relação às não adubadas, possibilitando pastejos ou cortes mais frequentes.

O efeito do uso de biofertilizante sobre o número de perfilhos quando não se adotou a adubação química se deve ao estimulo do $\mathrm{N}$ no crescimento e na multiplicação de células vegetais, com 
Quadro 5 - Taxa de aparecimento foliar (TApF) e filocrono do capim-piatã cultivado em ambiente protegido, recebendo biofertilizante com doses de adubo químico

\begin{tabular}{|c|c|c|c|c|c|c|c|c|}
\hline \multirow{2}{*}{$\begin{array}{l}\text { Adubação } \\
\text { Química }\end{array}$} & \multicolumn{5}{|c|}{ Doses de Biofertilizante (L) } & \multirow{2}{*}{ CV $(\%)$} & \multicolumn{2}{|c|}{$\begin{array}{c}\text { Valor P Efeitos } \\
\text { dose de biofertilizante }\end{array}$} \\
\hline & 0,0 & 1,0 & 2,0 & 3,0 & 4,0 & & $\begin{array}{l}\text { Uso de Bi- } \\
\text { ofertilizante }\end{array}$ & $\begin{array}{l}\text { Efeito } \\
\text { Linear }\end{array}$ \\
\hline \multicolumn{9}{|c|}{ NFV (folhas vivas perfilho-1) } \\
\hline Sem adubo & 6,62 & 7,25 & 7,87 & 8,00 & 7,75 & 7,20 & 0,002 & 0,21 \\
\hline $50 \%$ & 7,00 & 7,12 & 7,75 & 8,62 & 8,87 & 9,73 & 0,02 & 0,005 \\
\hline $100 \%$ & 7,25 & 8,37 & 8,75 & 9,25 & 9,00 & 9,80 & 0,001 & 0,22 \\
\hline \multicolumn{9}{|c|}{ Número de perfilhos vivos vaso-1 } \\
\hline Sem adubo & 0,25 & 1,00 & 1,75 & 2,00 & 1,75 & 77,09 & 0,03 & 0,32 \\
\hline $50 \%$ & 0,75 & 1,25 & 1,50 & 2,50 & 1,75 & 74,96 & 0,14 & 0,55 \\
\hline $100 \%$ & 1,25 & 1,75 & 2,00 & 2,75 & 2,50 & 49,18 & 0,09 & 0,30 \\
\hline
\end{tabular}

consequente aumento no número de perfilhos na planta (Oliveira et al., 2007).

Segundo Silva et al. (2009) o aumento no número de perfilhos nas plantas é de fundamental importância na redução da degradação das pastagens, tendo em vista que, proporciona maior cobertura do solo, diminuindo a exposição ao impacto da chuva e ao sol.

Quando se trabalhou com 50 e 100\% da adubação química recomendada, não se observou efeito $(\mathrm{P}<0,05)$ das doses de biofertilizante sobre o perfilhamento. Isso provavelmente ocorreu devido ao aumento na disponibilidade de $\mathrm{N}$ para as plantas, diminuindo a concorrência entre estas e otimizando o crescimento vegetativo em vez da emissão de novos perfilhos (Vasconcelos et al., 2013).

Pode-se observar que o capim-piatã respondeu de forma positiva a aplicação de $3 \mathrm{~L}$ por vaso de biofertilizante (correspondente a $400 \mathrm{~L} \mathrm{ha}^{-1}$ ), com ponto de máxima média (melhor resposta morfológica) para todas as variáveis morfogênicas e estruturais, exceto a TSeF. Isso foi observado na TAlC e no número de perfilho vivos por vaso em todas as condições de adubação química. Já na TAlF o ponto máximo de desenvolvimento, foi observado nos níveis sem adubação, enquanto que DVF e TApF foi observado quando se trabalhou com $50 \%$ da recomendação da adubação química.
Observa-se também que a aplicação de $3 \mathrm{~L}$ por vaso biofertilizante obteve o melhor desenvolvimento sobre o Filocrono, quando combinado com a suplementação de 50 e $100 \%$ da recomendação de adubação química. Já para o NFV o melhor desenvolvimento foi observado quando não se adotou a adubação química e com 100\% da recomendação.

Oliveira et al. (2008) afirmaram que redução no desenvolvimento das plantas, com elevadas doses de adubo orgânico, se deve ao desbalanço nutricional, ocasionando excesso de nutrientes no solo, com consequente efeito tóxico as plantas. Melo et al. (2011) relataram que aplicação de grandes quantidades de adubo orgânico, acaba por dificultar a absorção de nutrientes e as trocas gasosas do solo, em função de uma selagem que se forma na pequena área da superfície do solo no vaso.

\section{CONCLUSÕES}

A utilização de 3 litros de biofertilizante por $15 \mathrm{dm}^{3}$ de solo, independente do uso ou não e do nível de adubação química utilizada, mostrou-se eficiente na melhoria das características morfogênicas e estruturais do capim-piatã, na sua implantação. Assim, recomenda-se a realização de pesquisa em campo para monitoramento da evolução das condições de solo e do efeito de corte nestas condições. 


\section{REFERÊNCIAS BIBLIOGRÁFICAS}

Alexandrino, E.; Nascimento Júnior, D.; Mosquim, P.R.; Regazzi, A.J. \& Rocha, F. (2004) - Características morfogênicas e estruturais na rebrotação da Brachiaria brizantha cv. Marandu submetida a três doses de nitrogênio. Revista Brasileira de Zootecnia, vol. 33, n. 6, p. 1372-1379. http://dx.doi.org/10.1590/S1516-35982004000600003

Andrade, A.C.; Fonseca, D.M.; Gomide, J.A.; Alvarez, V.H.; Martins. C.E. \& Souza, D.P.H. (2000) Produtividade e valor nutritivo do capim-elefante cv. Napier sob doses crescentes de nitrogênio e potássio. Revista Brasileira de Zootecnia, vol. 29, n. 6, p. 1589-1595. http://dx.doi.org/10.1590/S1516-35982000000600001

Da Silva, T.C.; Perazzo, A.F.; Macedo, C.H.O.; Batista, E.B.; Pinho, R.M.A.; Bezerra, H.F.C. \& Santos, E.M. (2012) - Morfogênese e estrutura de Brachiaria decumbens em resposta ao corte e adubação nitrogenada. Archivos de Zootecnia, vol. 61, n. 233, p. 91-102. http://dx.doi.org/10.4321/S0004-05922012000100010

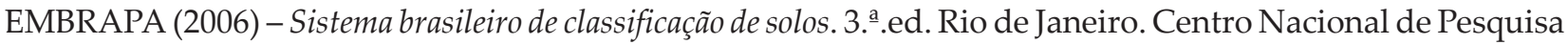
de Solos, Empresa Brasileira de Pesquisa Agropecuária (EMBRAPA), 412 p.

Fagundes, J.L.; Fonseca, D.M.; Mistura, C.; Morais, R.V.; Vitor, C.M.T.; Comide, J.A.; Nascimento Junior, D.; Casagrande, D.R. \& Costa, L.T. (2006) - Características morfogênicas e estruturais do capim-braquiária em pastagem adubada com nitrogênio avaliada nas quatro estações do ano. Revista Brasileira de Zootecnia, vol. 35, n. 1, p. 331-339. http://dx.doi.org/10.1590/S1516-35982006000100003

Gomes, M.B.; Banys, V.L.; Santos, J.; Castro, A.L.A.; Saenz, E.A.C. \& Fialho, C.A. (2012) - Morfogênese na germinação e na fase de estabelecimento da Brachiaria ruziziensis submetida à adubação nitrogenada e potássica. Ciência Rural, vol. 42, n. 12, p. 2235-2241. http://dx.doi.org/10.1590/50103-84782012005000108

Lima, J.G.A.; Viana, T.V.A.; Sousa, G.G.; Wanderley, J.A.C.; Neto, L.G.P. \& Azevedo, B.M. (2012) - Crescimento inicial do milho fertirrigado com biofertilizante. Revista Agropecuária Científica no Semiárido, vol. 8, n. 1, p. 39-44.

Martuscello, J.A.; Fonseca, D.F.; Nascimento Júnior, D.; Santos, P.M.; Cunha, D.N.F.V. \& Moreira, D.F. (2006) - Características morfogênicas e estruturais de capim-massai submetido à adubação nitrogenada e desfolhação. Revista Brasileira de Zootecnia, vol. 35, n. 3, p. 665-671. http://dx.doi.org/10.1590/S1516-35982006000300006

Martuscello, J.A.; Fonseca, D.M.; Nascimento Júnior, D.; Santos, P.M.; Ribeiro Júnior, J.I.; Cunha, D.N.F.V. \& Moreira, L.M. (2005) - Características morfogênicas e estruturais do capim-xaraés submetido à adubação nitrogenada e desfolhação. Revista Brasileira de Zootecnia, vol. 34, n. 5, p. 1475-1482. http://dx.doi.org/10.1590/ $\underline{\text { S1516-35982005000500007 }}$

Mazzanti, A.; Lemaire, G. \& Gastal, F. (1994) - The effect of nitrogen fertilization upon the herbage production of tall fescue swards continuously grazed with sheep. 1. Herbage growth dynamics. Grass Forage Science, vol. 49, n. 2, p. 111-120. http://dx.doi.org/10.1111/j.1365-2494.1994.tb01983.x

Melo, J.C.; Santos, P.M.; Santos, A.C.; Alexandrino, E. \& Neto, J.J.P. (2011) - Respostas morfofisiológicas do capim-mombaça submetida a doses de resíduo líquido de laticínios. Revista Brasileira de Ciências Agrárias, vol. 54, n. 3, p. 247-258.

Mueller, S.; Wamser, A.F.; Suzuki, A. \& Becker, W.F. (2013) - Produtividade de tomate sob adubação orgânica e complementação com adubos minerais. Horticultura Brasileira, vol. 31, n. 1, p. 86-92. http://dx.doi. org/10.1590/S0102-05362013000100014

Oliveira, D.Q.L.; Carvalho, K.T.G.; Bastos, A.R.R.;Oliveira, L.C.A.; Marques, J.J.G.S.M. \& Nascimento, R.S.M.P . (2008) - Utilização de resíduos da indústria de couro como fonte nitrogenada para o capim-elefante. Revista Brasileira de Ciência do Solo, vol. 32, n. 1, p. 417-424. http://dx.doi.org/10.1590/S0100-06832008000100039

Oliveira, A.B.; Pires, A.J.V.; Neto, U.M.; Carvalho, G.G.P.; Veloso, M. \& Silva, F.F. (2007) - Morfogênese do capim-tanzânia submetido a adubações e intensidade de corte. Revista Brasileira de Zootecnia, vol. 36, n. 4, p. 1006-1013. http://dx.doi.org/10.1590/S1516-35982007000500004

Orrico Júnior, M.A.P.; Centurion, S.R.; Orrico, A.C.A. \& Sunada, N.D. (2012) - Effects of biofertilizer rates on the structural, morphogenetic and productive characteristics of Piatã grass. Revista Brasileira de Zootecnia, vol. 41, n. 6, p. 1378-1384. http://dx.doi.org/10.1590/\$1516-35982012000600009

Penteado, S.R. (2007) - Adubação orgânica - preparo de compostos e biofertilizantes. 2. ․ ed. Campinas. 156 p.

Pereira, V.V.; Fonseca, D.M.; Martuscello, J.A.; Braz, T.G.S.; Santos, M.V. \& Cecon, P.R. (2011) - Características morfogênicas e estruturais de capim-mombaça em três densidades de cultivo adubado com nitrogênio. Revista Brasileira de Zootecnia, vol. 40, n. 12, p. 2681-2689. http://dx.doi.org/10.1590/S1516-35982011001200010 
Primo, D.V.; Fadigas, F.S.; Carvalho, J.C.R.; Shmidt, C.D.S. \& Borges Filho, A.C.S. (2010) - Avaliação da qualidade nutricional de compostos orgânicos produzido com resíduos de fumo. Revista Brasileira de Engenharia Agrícola e Ambiental, vol.14, n. 7, p. 742-746.

Santos, L.C.; Bonomo, P.; Silva, V.B.; Patês, N.M.S.; Silva, C.C.F. \& Pires, A.J.V. (2009) - Características morfogênicas de braquiárias em resposta a diferentes adubações. Acta Scientiarum: Agronomy, vol. 31, n. 1, p. 221-226. http://dx.doi.org/10.4025/actasciagron.v31i2.7032

Shehata, S.M.; Abdel Azem, H.S.; El Yazied, A.A. \& El Gizawy, A.M. (2010) - Interactive effect of mineral nitrogen and biofertilization on the growth, chemical composition and yield of celeriac plant. European Journal of Scientific Research, vol. 47, n. 2, p. 248-255.

Silva, C.C.F.; Bonomo, P.; Pires, A.J.V.; Maranhão, C.M.A.; Patês, N.M.S. \& Santos, L.C. (2009) - Características morfogênicas e estruturais de duas espécies de braquiária adubadas com diferentes doses de nitrogênio. Revista Brasileira de Zootecnia, vol. 38, n. 4, p. 657-661. http://dx.doi.org/10.1590/\$1516-35982009000400010

Silveira, M.C.T.; Nascimento Júnior, D.; Silva, S.C.; Euclides, V.P.B.; Montagner, D.B.; Sbrissia, A.F.; Rodrigues, C.S.; Sousa, B.M.L.; Pena, K.S. \& Vilela, H.H. (2010) - Morphogenetic and structural comparative characterization of tropical forage grass cultivars under free growth. Scientia Agricola, vol. 67, n. 2, p. 136-142. http://dx.doi.org/10.1590/S0103-90162010000200002

Skinner, R.H. \& Nelson, C.J. (1995) - Elongation of the grass leaf and its relationship to the phyllochron. Crop Science, vol. 35, n. 1, p. 4-10. http://dx.doi.org/10.2135/cropsci1995.0011183X003500010002x

Sousa, G.G.; Santos, E.M.; Viana, T.V.A.;Oliveira, C.M.B.;Alvino, F.C.G. \& Azevedo, B.M. (2013) - Fertirrigação com biofertilizante bovino na cultura do feijoeiro. Revista Agropecuária Cientifica no Semiárido, vol. 9, n. 4, p. 76-82.

Souto, P.C.; Souto, J.S.; Santos, R.V.; Araújo, G.T. \& Souto, L.S. (2005) - Decomposição de estercos dispostos em diferentes profundidades em área degradada no semi-árido da Paraíba. Revista Brasileira de Ciência do Solo, vol. 29, n. 1, p. 125-130. http://dx.doi.org/10.1590/S0100-06832005000100014

Teles, T.G.R.M.; Carneiro, M.S.S.; Soares, I.; Pereira, E.S.; Souza, P.Z. \& Magalhães, J.A. (2011) - Produção e composição química da Brachiaria brizantha cv. MG-4 sob efeito de adubação com NPK. Acta Scientiarum. Animal Sciences, vol. 33, n. 2, p. 137-143. http://dx.doi.org/10.4025/actascianimsci.v33i29392

Vasconcelos, W.A.; Andrade, A.P.; Santos, E.M.; Edvan, R.L.; Silva, V.S. \& Silva, T.C. (2013) - Características morfogenéticas e produção do capim buffel adubado com digesta bovina sólida. Revista Brasileira de Saúde e Produção Animal, vol. 14, n. 1, p. 1-9.

Volenec, J.J. \& Nelson, C.J. (1983) - Responses of tall fescue leaf meristems to N fertilization and harvest frequency. Crop Science, vol. 23, n. 4, p. 720-724. http://dx.doi.org/10.2135/cropsci1983.0011183X002300040028x 